\title{
¿S Research Square

\section{A New Perspective For Improving The Human Resource Development of Primary Medical and Health Care Institutions: A Structural Equation Model Study}

Huanhuan Jia

Jilin University School of Public Health

\section{Peng Cao}

Jilin University School of Public Health

Jianxing Yu

Jilin University School of Public Health

Jingru Zhang

Jilin University School of Public Health

Hairui Jiang

Jilin University School of Public Health

Qize Zhao

Social Security Organization

Xihe Yu ( $\nabla$ xhyu@jlu.edu.cn )

Jilin University School of Public Health https://orcid.org/0000-0003-4151-0915

\section{Research}

Keywords: Health Workforce, Primary Medical and Health Care Institution, Implicit Theory, Lexical Methods

Posted Date: February 23rd, 2021

DOl: https://doi.org/10.21203/rs.3.rs-223067/v1

License: (9) This work is licensed under a Creative Commons Attribution 4.0 International License. Read Full License 


\section{Abstract}

Background: In China, primary health care is rarely utilized because of medical personnel shortages at primary medical and health care institutions (PMHCls). Several studies suggest that the most effective solution is to guide qualified doctors and medical graduates to work in PMHCls, but the studies and measures have been formulated only from the perspective of the government and PMHCls; few have considered the subjective willingness of medical personnel.

Methods: From the perspective of the guided objects, this research was divided into two parts based on implicit theory and a lexical method. The first part takes hospital clinical graduates and interns as the survey subjects and collects the factors affecting their choosing PMHCls for employment. The second part takes candidates for the medical licensing examination as the survey object and uses exploratory factor analysis (EFA), confirmatory factor analysis (CFA) and structural equation modeling (SEM) to explore the dimensions and paths of the influencing factors.

Results: Seven factors were obtained from the EFA, and the SEM hypothesis fits the data well. Internal Organization Development, Patient Factor, Remuneration and Development, and Family Support had a significantly positive effect on the Sense of Gain of medical personnel seeking employment at PMHCls, whereas both Job Responsibilities and Condition of the City Where the PMHCI Is Located had no significant effect. In addition, the indirect effects of Internal Organization Development and Condition of the City Where the PMHCI Is Located on the Sense of Gain were significant. The Patient Factor, Family Support, and Remuneration and Development significantly mediated the relationship between the internal and external environment of the institution and the Sense of Gain, whereas the mediating effect of Job Responsibilities was not significant.

Conclusions: The improvement of family support, remuneration and development and patient factors increases the willingness of medical personnel to seek employment at PMHCls. In addition, the internal and external environments of a $\mathrm{PMHCl}$ play a vital role in guiding medical personnel to $\mathrm{PMHCls}$ for employment. This research provides theoretical support for improving the development of human resources, guiding medical personnel to work in PMHCls, and promoting the implementation of medical and health system reform in China.

\section{Background}

Primary health care has attracted attention in many countries, and a series of measures have been taken to promote access to primary health care, such as India's rural health centers[1], Nepal's primary healthcare (PHC) system[2], and the Affordable Care Act (ACA) in the United States[3]. In China, primary health care is undertaken by primary medical and health care institutions ( $\mathrm{PMHCls}$ ), primarily community health service centers and township hospitals, which provide general clinical care and basic public health services to residents $[4,5]$. Recognizing the double burden of the prevalence of chronic noncommunicable diseases[6] and increasing health costs[7] caused by population aging[8, 9], behavioral changes[10], and 
rapid urbanization[11], the Chinese government began to reform the medical and health care system in 2009. In this reform, the improvement of the primary medical service system was one of the five key issues[5, 12], and a hierarchical medical system was proposed to effectively balance various medical service resources and divert the general outpatient, rehabilitation, and nursing care originally undertaken by large and medium-sized medical institutions to PMHCIs[13, 14], highlighting the role of these facilities. Since then, a considerable amount of money has been invested to improve the service capacity and quality of PMHCIs $[15,16]$, and as a result, the facilities and environment of PMHCls have been improved. However, the services provided by PMHCls are rarely utilized[17, 18], and the operation of PMHCls is poor because of the lack of service uptake by patients[13,19]. Previous surveys[20-22] have shown that patients' distrust of PMHCls is one important reason for this, and the paucity and low technical level of medical personnel caused by their attrition is one of the important sources of this distrust. Therefore, increasing the number and technical capacity of medical personnel[23] in PMHCls is an urgent measure in China's implementation of primary health care and promotion of medical and health reform.

The Chinese government has developed various types of training and practice systems for general practitioners to strengthen the human resource development of $\mathrm{PMHCls}$ [24]. Previous studies have proposed that the government and PMHCls should focus on addressing medical personnel's work status and work-related demands[25], balancing their work pressures[26], improving their financial remuneration[27], providing more opportunities for learning, training and individual development[28], increasing their work passion and enthusiasm, reducing their attrition, and improving their technical skill level. However, it will take a long time to train a sufficient number of general practitioners[13], and formulating incentives to reduce the loss of medical personnel cannot completely compensate for the shortage of medical personnel in PMHCls. Therefore, we recommended that the most effective solution is to guide qualified doctors[29] and medical graduates[13] to seek employment at PMHCls. In China, the candidates who take the medical licensing examination have received systematic clinical skills training, and most of them are medical graduates or unemployed interns who are seeking a job; it is this group that is most susceptible to guidance. In addition, we found that previous studies lacked in-depth research on specific guidance measures, and most of the measures were formulated from the perspective of government and PMHCls without comprehensive exploration and discussion of various factors such as family, the local economy and cultural from the perspective of medical personnel. We emphasize that medical personnel in $\mathrm{PMHCls}$ are not only the main providers of primary health care but also direct participants in promoting the reform of China's medical and health system; thus, the role of medical personnel should be changed from passive recipients of policies to participants in making policies. Therefore, this paper took the candidates for the medical licensing examination as the research object and analyzed the factors that affected their choice to seek employment at PMHCls and the relationships among them from the guided objects' own perspective.

Implicit theory refers to people's views on the conceptualization, structure and development process of certain psychological characteristics that are formed in the context of daily life and work and exist in the individual's mind in some form and can accurately and fully reflect people's mental representations[30]. The role of implicit theory in information organization and interpretation has been increasingly accepted 
by cognitive psychologists and social psychologists[31] and has been extended to self-regulation[32], leadership effectiveness[33, 34], emotional and mental health[35], wisdom[36, 37], and creative performance[38] in recent years. In addition, the lexical approach was originally used by psychologists to study personality traits, and it is based on the hypothesis that the individual differences that are of most significance in the daily transactions of persons with each other eventually become encoded in their language[39-41]. The lexical method provides a research strategy aimed at identifying a set of relatively small, roughly independent axes along which people's typical behavioral tendencies differ[39]. The argument here is that in the general context of China's medical and health reform, candidates are definitely exposed to information about PMHCls in their lives and work, and this information is encoded in their minds and language, manifesting in candidates' attitudes and views towards PMHCls.

Therefore, implicit theory was applied as the starting point, and the lexical approach was used to explore the attitudes of candidates who were taking the medical licensing examination regarding seeking employment at PMHCls. This paper was divided into two parts according to the procedure of lexical studies[42, 43]. The first step was a pre-investigation to collect influencing factors, and the second step was a formal investigation to explore the dimensions and relationships of the influencing factors.

\section{Pre-investigation}

\section{Participants and Procedures}

Due to the brevity of the exam period, the pre-investigation and formal investigation could not be completed at the same time, so we chose an alternative population in which to conduct the preinvestigation. Given that students and interns who are about to graduate or are participating in standardized resident training at a hospital are either preparing for or have just finished the medical licensing examination and are searching for a job, their profile is consistent with that of the groups targeted by our research. Therefore, groups of students and interns from two hospitals who were involved in medical, teaching, and scientific research tasks were selected as the subjects of the pre-investigation.

A data collection service from a leading Chinese online survey site was adopted to administer the preinvestigation. First, we contacted the hospital training department that manages students and interns and requested that the online questionnaire be sent to the target group and asked the respondents to complete the survey within a certain period of time. A total of 367 students and interns participated in the pre-investigation, but 15 people had signed an employment contract with a hospital, 5 were majoring in preventive medicine, and 3 filled in "None" for influencing factors. Ultimately, 344 complete and valid responses were obtained, and the effective response rate was $93.66 \%$. In this sample, most of the respondents were women $(74.71 \%)$, were majoring in clinical medicine $(90.70 \%)$, and had a college or graduate degree $(98.06 \%)$, and the mean age was $25.76( \pm 2.81)$. Our study procedures were approved by the Medical Ethics Committee of the School of Public Health Jilin University (No. 20181102). According to ethical standards and practices, participants received a complete explanation of the research purpose. 
In addition, they were told that the information collected would be used only for research purposes and that they could withdraw from the study at any time.

\section{Measures}

A questionnaire containing open-ended questions was used, and the respondents were asked to answer the following question: "If a PMHCl was recruiting medical personnel, what factors would influence you to seek employment with a PMHCl? Please write down these factors in simple words or phrases." The questionnaire also collected the sociodemographic characteristics of the students and interns, including gender, age, marital status, education level, and major. To ensure data quality and reduce social desirability bias, we adopted several relevant measures in the questionnaire design and data cleaning. For example, we set up screening questions to ensure that the answers came from eligible respondents, including "Are you a regular employee of the hospital?", "Have you signed an employment contract with a hospital?", and "What is your major?". In addition, methods such as IP confirmation, answering time and empty item review were used to ensure the quality of the data provided.

\section{Data Analysis}

Ultimately, 1439 items were obtained from the pre-investigation. However, many words were repeated, and some concepts were expressed in complex phrases or sentences, so we cleaned and organized the lexical data without changing the meaning. The principles were as follows: (1) Remove modifiers such as adjectives and adverbs to extract key information; for example, "High wage level" and "Well-paid" were recoded as "Wage", and "The primary medical institution is close to home" was recoded as "Distance from home". (2) Combine synonymous words; for example, "High wage level" and "Well-paid" were combined into "Wage", and "House issues" and "Accommodation environment" were combined into "Housing". (3) Split combined concepts; for example, "What is the environment and economy of the institution's location" was divided into "The environment of the city where the $\mathrm{PMHCl}$ is located" and "The economy of the city where the PMHCl is located", and "Whether my wife and parents agree" was divided into "Spouse" and "Parents". (4) Delete words obviously irrelevant to our research, such as the names of people, places and institutions.

Finally, all factors were recoded into 103 items. The results showed that 51 of these items had a frequency of less than 4 ; that is, these factors were mentioned by less than $1 \%$ of the students and interns. Because of their lack of representativeness, these items were deleted from the formal investigation. Finally, without changing the meaning of the vocabulary, 52 factors were adjusted and normalized and then used for the preparation of the questionnaire.

\section{Investigation}

\section{Materials and Methods}

\section{Participants and Procedures}


The subjects of the investigation were all candidates who signed up for the medical licensing examination at a site in Changchun, Jilin Province. Our study procedures were approved by the Medical Ethics Committee of the School of Public Health Jilin University (No. 20181102) too. The investigators were a postgraduate team from the School of Public Health at a university. We contacted the Changchun Medical Examination Center and asked it to cooperate with us in completing the research work. During the investigation, the investigator explained in advance the purpose and filling requirements of the questionnaire and informed the candidates that participation was voluntary. The questionnaires were then distributed to the candidates and retrieved immediately upon completion.

After data collection, all paper questionnaires were manually entered into a computer database, and items with empty or invalid data were dropped from further analysis. Ultimately, 1778 complete and valid responses were obtained. In this sample, most of the respondents were women (60.74\%), were majoring in clinical medicine $(81.72 \%)$, had a college degree $(80.82 \%)$, and were studying or working in tertiary hospitals $(64.64 \%)$, and the mean age was $29.08( \pm 5.57)$.

\section{Measures}

The 52 factors from the pre-investigation were used to create the main part of the questionnaire. The question was "If a $\mathrm{PMHCl}$ was recruiting medical personnel, please rate the importance of the following factors in their influence on your choice to seek employment at a $\mathrm{PMHCl}$ based on your actual situation", and we used a 5-point Likert scale to measure the factors, with anchors ranging from 1 (very unimportant) to 5 (very important). Further, the sociodemographic characteristics of the respondents were collected by the questionnaire (gender, age, degree, major, and study or work institution).

\section{Data Analysis}

To explore the factors influencing medical personnel to seek employment at a $\mathrm{PMHCl}$ and their relationship, we need to not only explore the underlying structure of the factors but also conduct a hypothesis test on this structure. Therefore, in the analysis process, half of the sample was chosen randomly for exploratory factor analysis (EFA), which was used to extract common factors from the items and obtain concise and representative factors and then put forward a hypothesized model. Then, for the other half of the sample, confirmatory factor analysis (CFA) was adopted to test the reliability and validity of the dimensions, and finally, structural equation modeling (SEM) was applied to test the hypothesis.

Specifically, EFA was used for the first sample, in which principal component analysis (PCA) was performed to extract the factors, and varimax rotation (VR) was used to improve the interpretability of the solution[44, 45]. SPSS software (version 23.0) was used for this process. For the second sample, AMOS software (Version 24.0) was used for CFA and SEM. In this part, we performed SEM following the twostep approach recommended by Anderson and Gerbing[46]. First, CFA was carried out for each factor to test whether these factors had a significant factor loading index and to analyze the reliability and validity of the questionnaire. Second, based on the hypothesized path model, the SEM parameters were 
estimated by the maximum likelihood method. In addition, the model was assessed by the following model fit indexes, with the values in parentheses indicating the cutoffs for acceptable fit $[47,48]$ : (1) the chi-square value ( ); (2) the chi-square degrees of freedom ( /DF $<5)$; (3) the root mean square error of approximation (RMSEA $\leq 0.08$ ); (4) the comparative fit index (CFI $\geq 0.90)$; (5) the Tucker-Lewis index (TLI $\geq 0.90$ ); and (6) the incremental fit index (IFI $\geq 0.90$ ). All statistical tests were two-sided with the level of significance set at 0.05 . Finally, the bootstrap method was used to test the potential mediator effects, and we calculated the total, direct and indirect effects.

\section{Exploratory Factor Analysis and Research Hypotheses}

\section{Exploratory Factor Analysis}

The EFA results showed that the Kaiser-Meyer-Olkin (KMO) value was 0.966 , which was higher than 0.6, indicating the appropriateness of conducting EFA[49]. Further, the result of Bartlett's test was significant ( $=33912.366, \mathrm{P}<0.001$ ), indicating that the relationship among the items was strong and that the data were suitable for EFA[50].

Seven factors with eigenvalues greater than one were extracted from the first EFA, and their cumulative contribution rate reached $64.874 \%$. However, six items were gradually deleted because the factor loadings were less than 0.45 or higher than 0.4 on two or more factors simultaneously[51]: Social Position of Medical Personnel, Government Policy Support, Number of Patients, Skill of Existing Personnel, Economy of the City Where the PMHC Is Located, and Organizational Culture. Finally, seven factors were extracted from the remaining 46 items, and their cumulative contribution rate reached $66.896 \%$. Detailed results of the final EFA are shown in the attachment.

\section{Factors Analysis and Research Hypotheses}

Sense of Gain (SG)

There were 3 items in this factor: Professional Pride, Fulfill Personal Value and Job-Related Well-being. First, the medical profession has the vital responsibility of providing medical and health services and safeguarding people's health[52], so the sense of professional pride is high and is closely related to the work quality, job satisfaction and intention to leave of medical personnel[53-55]. Second, in China, the upfront investment of medical personnel, in terms of education and training time, is often longer than that of workers in other industries, and they need considerable knowledge, training and practice to be competent or obtain professional titles[56]. It is thus particularly important for medical personnel to demonstrate their personal value in their work. Finally, Job-Related Well-being is the emotional response of employees at work. Negative emotions can lead to stress, depression and anxiety, while positive emotions can help people thrive in the face of difficulties[57, 58]. Moreover, Job-Related Well-being has been identified as a key area for attracting and retaining employees[59-61], and it also played a decisive role in employment willingness [62], so we proposed that the manifestation of Sense of Gain determined whether medical personnel were amenable to seeking employment at a $\mathrm{PMHCl}$. Therefore, Sense of Gain 
was used as a dependent variable to explore the relationship between various factors and the willingness of medical personnel seeking employment at PMHCls.

Remuneration and Development (RD)

This factor included 11 items, including Wage, Working Bonus, Social Insurance and Accumulation Fund, Position and Professional Title Promotion, etc. These items reflect the concerns about the Remuneration and Development that can be obtained by seeking employment at PMHCls. Wages and individual development have always been common issues of concern to career groups. For medical personnel, the investment of time and money and the difficulty of obtaining a professional title[56] make them sensitive to remuneration and development issues. In addition, previous studies[27, 63, 64] have reported that remuneration and development are also important factors that affect the work satisfaction and enthusiasm of community health workers. Therefore, we recommended that the sense of gain of medical personnel seeking employment at $\mathrm{PMHCls}$ can be increased through appropriate remuneration and development opportunities.

Internal Organization Development (IOD)

This factor includes 12 items, including Department Setting, Software and Hardware Facilities, Human Resource Allocation, Organizational Management System, Culture and Working Environment, etc. Several studies[65-68] have documented that an organization's internal development is fundamental to the turnover tendency, happiness, job satisfaction and burnout of medical personnel. Besides, this internal development reflects the diagnosis and treatment capabilities of the institution, and affects patients' identification with PMHCls and willingness to seek treatment[69, 70]. We proposed that, on the one hand, Internal Organization Development is related to medical personnel's work arrangements, work pressure, and workload and to the Remuneration and Development, which affects the Sense of Gain of medical personnel seeking employment at PMHCls as well as patients' willingness to seek medical treatment in PMHCls.

Condition of the City Where the PMHCI Is Located (CCPL)

There are 7 items in this factor, including the city's Development, Environment, Transportation, Culture and Customs, Economy, and Distance from Home and the Reputation of PMHCl Where the PMHCl Is Located. These items reflect the fact that medical personnel not only pay attention to an organization's internal development but are also concerned about the external environment of the PMHCl. Besides, medical personnel's wages, individual development, family, and doctor-patient relations are affected by the condition of the city where the $\mathrm{PMHCl}$ is located, including economy, culture and customs, which certainly affect their sense of gain as well.

Job Responsibilities (JR)

This factor includes five items: Work Intensity, Stress, Hours, Workload, and Post of Duty. These items reflect medical personnel's concern about their specific work content and job responsibilities. Several 
studies[71, 72] have documented that job characteristics are important predictors of job-related happiness. In addition, the arrangement of the work is determined by an organization's internal development. Therefore, we proposed that Internal Organization Development affects Job Responsibilities and that Job Responsibilities affect the Sense of Gain.

Family Support (FS)

This factor includes 4 variables, Spouse, Children, Parents and House, which represent the family factors considered when medical personnel seek employment at a PMHCI. Studies[73] have pointed out that family support can buffer employees' job stress and prevent negative work-related outcomes such as job burnout, and family members have also been shown to provide both instrumental and affective support, which positively affect employee's work life[74]. Medical personnel are no exception; a meta-analysis[75] showed that the conflict between work and family has a strong impact on the high turnover rate of medical personnel, and reducing this conflict can improve their happiness[76]. In addition, communication research[77] has shown that the family as a socialization agent conveys both extrinsic and intrinsic work values for developing a professional identity. Therefore, we propose that Family Support will have a positive impact on the professional identity and work enthusiasm of medical personnel and will inevitably be affected by the Condition of the City Where the PMHCI Is Located via the economy, culture, etc.

Patient Factor (PF)

This factor includes local patients' Trust and Respect in Physicians, the Doctor-Patient Relationship and the Moral Character of the Patients. Globally, the concept of medical service has changed from being doctor-centric to patient-centric, which reduces physician dominance, advocates greater patient control, and encourages more mutual participation[78]. However, the lack of coordination and conflict between doctors and patients has aroused widespread concern in society and academia, and it is becoming a serious dilemma facing the medical industry and even society as a whole[79-82]. As such, it is having a substantial impact on the working conditions and psychological pressure experienced by medical personnel[ $[83,84]$, and it is likely to lead to work fatigue[85]. Studies[86, 87] have pointed out that the doctor-patient relationship is also an important factor affecting the resignation or career choices of medical personnel. Therefore, we propose that the character, trust in $\mathrm{PMHCls}$, and respect for medical personnel can reduce work pressure and increase enthusiasm and job-related well-being. In addition, the Condition of the City Where the PMHC Is Located factor, as represented by the city's economy, culture, etc., can also affect patients' attitude toward PMHCls.

Based on the above discussion, the following research hypotheses were proposed:

Hypothesis 1 (H1). Internal Organization Development has a positive effect on Sense of Gain.

Hypothesis $2(\mathrm{H} 2)$. Condition of the City Where the PMHCl Is Located has a positive effect on Sense of Gain. 
Hypothesis $3(\mathrm{H} 3)$. Remuneration and Development have a positive effect on Sense of Gain.

Hypothesis 4 (H4). Family Support has a positive effect on Sense of Gain.

Hypothesis 5 (H5). Patient Factor has a positive effect on Sense of Gain.

Hypothesis $6(\mathrm{H} 6)$. Job Responsibilities have a positive effect on Sense of Gain.

Hypothesis 7 (H7). Internal Organization Development has a positive effect on the Patient Factor.

Hypothesis $8(\mathrm{H} 8)$. Condition of the City Where the PwwwMHCl Is Located has a positive effect on the Patient Factor.

Hypothesis 9 (H9). Internal Organization Development has a positive effect on Remuneration and Development.

Hypothesis $10(\mathrm{H} 10)$. Condition of the City Where the PMHCl Is Located has a positive effect on Remuneration and Development.

Hypothesis 11 (H11). Internal Organization Development has a positive effect on Job Responsibilities.

Hypothesis $12(\mathrm{H} 12)$. Condition of the City Where the PMHCl Is Located has a positive effect on Family Support.

\section{Confirmatory Factor Analysis}

CFA was used to test the reliability and validity of our measurement instrument. In the process, nine variables were removed because the standardized factor loadings were lower than $0.7[88]$. These variables were Organizational Management System, Working Environment, Reputation of the $\mathrm{PMHCl}$, Availability of Drugs, Degree of Emphasis on Clinical, Institution Size, Level of Knowledge, Distance from Home and Post of Duty.

Finally, as shown in Table 1, all the Cronbach's alpha and composite reliability (CR) values were above 0.8 , indicating acceptable reliability for all constructs. Further, the average variance extracted (AVE) value of each construct was above 0.5[89], and the standardized factor loading of each item was above 0.7[47], indicating good convergent validity. In addition, as shown in Table 2 , the discriminant validity is verified because the square roots of the AVEs of each construct is higher than its correlation [90]. Therefore, we concluded that the remaining items have sufficiently good reliability and validity to test the structural model of our proposed hypotheses.

Since the data for all constructs were collected using the same measurement instrument, we tested the possibility of common method bias. First, the values of the correlation coefficients in Table 2 were all lower than 0.9 , indicating that there were no pairs with very strong correlations[47]. Second, the Harman single factor test was conducted by PCA, and the results showed that the first extracted factor in the 
unrotated solution accounted for $41.02 \%$ of the variance, which was less than $50 \%$ [91]. Finally, controlling for the effects of an unmeasured latent methods factor, common method bias was tested for. As shown in Table 3, after adding the common method factor, the variance of the fit index was very small, and even the RMSEA value decreased. Therefore, common method bias did not seem to affect the result.

\section{Structural Model Analysis}

Table 4 presents the fit of the structural equation model. As can be observed, the hypothesized model fits the data well. The $t$ values of each path were computed to test the hypothesized relationships in our research model in AMOS, and the results are shown in Figure 1. In the hypothesized model, Internal Organization Development $(\beta=0.154 ; P<0.001)$, the Patient Factor $(\beta=0.547 ; P<0.001)$, Remuneration and Development $(\beta=0.129 ; P=0.004)$, and Family Support $(\beta=0.081 ; P=0.018)$ had a significantly positive effect on the Sense of Gain of medical personnel seeking employment at PMHCls. Therefore, $\mathrm{H} 1, \mathrm{H} 3, \mathrm{H} 4$ and $\mathrm{H} 5$ were supported, whereas the hypotheses regarding Job Responsibilities $(\beta=0.055 ; P=0.053)$ and Condition of the City Where the PMHCI Is Located $(\beta=0.022 ; P=0.652)$ were not supported. In addition, both Internal Organization Development $(\beta=0.377 ; P<0.001, \beta=0.344 ; P<0.001)$ and Condition of the City Where the PMHCI Is Located $(\beta=0.460 ; P<0.001, \beta=0.497 ; P<0.001)$ had significantly positive effects on Patient Factor and Remuneration and Development, so H7, H8, H9 and H10 were all supported. Finally, Internal Organization Development $(\beta=0.283 ; P<0.001)$ had a significantly positive effect on Job Responsibilities, and Condition of the City Where the PMHCI Is Located $(\beta=0.523 ; P<0.001)$ had a significantly positive effect on Family Support, indicating that $\mathrm{H} 11$ and $\mathrm{H} 12$ were supported. The results provide a useful theoretical perspective for taking corresponding measures to guide medical personnel toward work in PMHCls.

In addition, to test the mediating role of the Patient Factor, Family Support, Job Responsibilities, and Remuneration and Development, we applied the bootstrapping technique in AMOS[92, 93]. A 95\% confidence interval of the indirect effects was obtained with 5000 bootstrap resamples. As shown in Table X, the indirect effects of Internal Organization Development and Condition of the City Where the $\mathrm{PMHCl}$ Is Located on Sense of Gain are the significant. The Patient Factor, Family Support, and Remuneration and Development significantly mediated the relationship between the internal and external environment of the institution and Sense of Gain, whereas the mediating effect of Job Responsibilities was not significant.

\section{Discussion}

In this paper, we investigated the factors that influence medical personnel to seek employment in PMCHIs based on implicit theory and a lexical approach. Through a pre-investigation and investigation, 7 factors were obtained, namely, Sense of Gain, Remuneration and Development, Internal Organization Development, Condition of the City Where the PMHCI Is Located, Job Responsibilities, Family Support and the Patient Factor. In addition, SEM was applied to explore the interrelationships and path of each factor. Our results are sound and robust for the following reasons. First, a pre-investigation was used to 
collect the factors, and an investigation was used to propose and verify the theoretical hypotheses, so the research design was highly scientific. Second, the soundness of the data collection process was guaranteed by several measures, such as screening questions, IP confirmation, answering time and empty item review. Therefore, the authors believe that this paper provides a theoretical reference allowing the government and PMHCls to take adopt measures to strengthen the development of health human resources in PMHCls.

The results showed that the Remuneration and Development factor had the most items, indicating that medical personnel paid the most attention to it and that it positively affected the willingness of medical personnel to turn to $\mathrm{PMHCls}$ for employment. This factor not only represents a common requirement of job seekers but also relates to the specific remuneration and development status in PMHCls. In other words, the low remuneration and poor individual development opportunities of medical personnel have increased job burnout and the turnover rate and have resulted in low satisfaction, serious attrition among medical personnel and difficulty recruiting personnel to PMHCls. Therefore, remuneration and development have become an important focus for medical personnel seeking employment in PMHCls. More importantly, we found that the Internal Organization Development and Condition of the City Where the PMHCI Is Located factors had a significantly positive effect on Remuneration and Development, indicating that the optimization of the internal and external conditions of the institution with respect to department construction, facilities, learning atmosphere, and scientific research and the development and environment of the city where a $\mathrm{PMHCl}$ is located can increase perceptions of remuneration and development among medical personnel in PMHCls. Therefore, when guiding medical personnel to work in PMHCls, it is not sufficient to consider remuneration and development separately; this factor should be analyzed in conjunction with the development of the institution and of the city. The absence of any one subfactor could reduce the motivation of medical personnel to turn to PMHCls for employment, and only when the three factors reach a certain level can primary medical institutions successfully recruit and retain medical personnel. In short, complete and excellent development of institutions and cities as well as remuneration and development opportunities of corresponding quality can effectively encourage medical personnel to work in PMHCls.

The Patient Factor was an unexpected factor that significantly affected the Sense of Gain of medical personnel seeking employment in $\mathrm{PMHCls}$, and it provided a new perspective for guiding medical personnel to work in such institutions. By analyzing the items contained in the Patient Factor, we found that Patients' Trust and Respect toward medical personnel were an important embodiment of Professional Pride and Value, and the Patient-Doctor Relationship and Moral Character of the Patients were also important aspects of Job-Related Well-being, so the Patient Factor was closely related to the Sense of Gain factor. In addition, the subfactors of Internal Organization Development, such as Software and Hardware Facilities and Department Setting, positively affect Patients' Trust and Respect. In addition, the culture, folk customs and development of the city where the institution is located also positively affect patients' moral character, the doctor-patient relationship and their trust in $\mathrm{PMHCls}$. Therefore, we propose that the improvement of PMHCls development and the continuous improvement of patients' awareness of the role of PMHCls in the hierarchical diagnosis and treatment system can increase 
patients' trust in and satisfaction with PMHCls, thereby increasing the willingness of medical personnel to turn to $\mathrm{PMHCls}$ for employment.

Family Support had a positive and significant impact on Sense of Gain, indicating that if factors such as family members and housing for medical personnel were fully considered, the willingness of medical personnel to seek employment at PMHCls would increase. Moreover, Condition of the City Where the $\mathrm{PMHCl}$ Is Located positively and significantly affected Family Support, suggesting that the living and working conditions of medical personnel's family members need to be considered when guiding medical personnel; to turn to $\mathrm{PMHCls}$ for employment.

Job Responsibilities was an important factor influencing the willingness of medical personnel to seek employment at PMHCls, but the results showed that the correlation between Job Responsibilities and Sense of Gain was not significant. The main reason is likely that most of the participants who were facing job selection or undergoing pre-job selection training were in large hospitals with scientific research and teaching qualifications, and the gap between a large hospital and PMHCls in terms of work pressure, workload, and work difficulty is large. Therefore, the medical personnel had less awareness of the specific job responsibilities at PMHCls. However, against the backdrop of integrating public health services and clinical services, the medical personnel in PMHCls have taken on expanded roles[94, 95], so they are under considerable pressure. In addition, it has been shown that workload, work intensity, and work pressure are important factors that affect the satisfaction and willingness to quit of medical personnel in PMHCls $[65,85,96]$. Therefore, this study proposes that although the participants had not yet clarified the relationship between their job responsibilities and sense of gain, Job Responsibilities is still an important factor affecting the work of medical personnel in PMHCls.

The relationship between Internal Organization Development and Sense of Gain was positively significant, indicating that departments with a scientific setting, software and hardware facilities, and a higher scientific research level improve the work experience of medical personnel and thereby improve the willingness of medical personnel to seek employment at a PMHC. In addition, Internal Organization Development indirectly affected Sense of Gain through the Patient Factor and Remuneration and Development. Thus, the scientific and complete development of the internal organization of PMHCls not only affects the willingness of medical personnel directly but also improves patients' trust in and respect for PMHCls, increases their remuneration, and creates individual development opportunities, all of which improve the willingness of medical personnel to seek employment at a $\mathrm{PMHCl}$.

Regarding the insignificant effect of Condition of the City Where the PMHCl Is Located on Sense of Gain, it may be that compared to the weight given to the external environment, medical personnel pay more attention to proximal factors such as individuals, family and internal development. However, through the analysis of the mediation effect, the influence of the condition of the city on personnel's sense of gain cannot be ignored; that is, it can affect Sense of Gain through the Patient Factor and Remuneration and Development. Therefore, we conclude that Condition of the City Where the PMHC Is Located has an 
indirect and vitally important impact on the willingness of medical personnel to seek employment in PMHCls.

\section{Strengths and limitations of this study}

The major strengths of this study include the following aspects. First of all, this study took the candidates for the medical licensing examination as the research object who were facing graduation or career choice, and were a suitable group to be guided to work in PMHCls. Previous studies had not paid attention to this population, so the study provides a new perspective for improving the human resources development of PMHCls. Second, the analysis from the perspective of the guided object solves the defect that the original measures were only formulated from the perspective of the government and PMHCls and lacked understanding of the actual needs of medical personnel. Third, this study analyzed the factors such as the internal and external environment of the institution, family, patients, remuneration and individual development on the willingness of medical personnel seeking employment at PMHCls, and the factors involved are comprehensive and representative. However, this study also has three limitations. First, because of the characteristics of the candidates, they did not represent all categories of medical personnel. Second, attitudes vary from region to region, so further analysis based on local conditions. Third, this study is a cross-sectional analysis, and it is impossible to determine the changes in the attitude of medical personnel over time.

\section{Conclusion}

This study uses implicit theory and a lexical approach to explore the factors that affect candidates who are facing career choices to seek employment at PMHCls. We analyzed the relationship among the following factors that influence medical personnel's decision to seek employment at a PMCHI: Remuneration and Development, Internal Organization Development, Condition of the City Where the $\mathrm{PMHCl}$ Is Located, Job Responsibilities, Family Support, the Patient Factor, and Sense of Gain.

We conclude that the improvement of Family Support, Remuneration and Development, and Patient Factors will increase the willingness of medical personnel to turn to PMHCls for employment. In addition, the Internal Organization Development factor has both direct and indirect effects on this willingness through the Patient Factor and Remuneration and Development, whereas Condition of the City Where the $\mathrm{PMHCl}$ Is Located has indirect effects on willingness through the Patient Factors, Remuneration and Development, and Family Support. Therefore, the internal and external environments of a PMHCl play a vital role in guiding medical personnel to $\mathrm{PMHCls}$ for employment. This research provides theoretical support for improving the development of human resources, guiding medical personnel to work in PMHCls, and promoting the implementation of the hierarchical diagnosis and treatment system.

\section{Abbreviations}


PMHCls: Primary medical and health care institutions; SG: Sense of Gain; RD: Remuneration and Development; IOD: Internal Organization Development; CCPL: Condition of the City Where the PMHCI Is Located; JR: Job Responsibilities; FS: Family Support; PF: Patient Factor. AVE: average variance extracted; EFA: exploratory factor analysis; CFA: confirmatory factor analysis; SEM: structural equation modeling; VR: varimax rotation; PCA: principal component analysis; RMSEA: the root mean square error of approximation; CFI: the comparative fit index; TLI: the Tucker-Lewis index; IFI: the incremental fit index.

\section{Declarations}

\section{Ethics approval and consent to participate}

Our study procedures were approved by the Medical Ethics Committee of the School of Public Health Jilin University (No. 20181102). We had fully communicated with hospitals and examination centers. At the same time, in accordance with ethical standards and practices, participants received a complete explanation of the research purpose and guarantees of confidentiality.

\section{Consent for publication}

Not applicable.

\section{Availability of data and materials}

The datasets used and/or analysed during the current study are available from the corresponding author on reasonable request.

\section{Competing interests}

The authors declare that they have no competing interests.

\section{Funding}

This work was supported by MOE (Ministry of Education in China) Project of Humanities and Social Sciences [Grant No.18YJAZH118]. The funding agencies had no role in design, analysis, interpretation, or writing of this study.

\section{Authors' contributions}

$\mathrm{XH}$ Y conceived and designed the study, and revised and approves the final version of the manuscript. $\mathrm{HH}$ $\mathrm{J}$ designed the questionnaire and the survey, analyzed the data and drafted the manuscript. PC, JX Y, and JR Z carried out the acquisition of data, questionnaires, and measures design, and participated in data analysis. HR J and QZ Z carried out the planning of data collection and contributed in review and editing of the manuscript. All authors read and approved the final manuscript.

\section{Acknowledgements}


The authors gratefully acknowledge cooperation of the hospitals and examination center in the data collection process.

\section{References}

1. Magnussen L, Ehiri J, Jolly P: Comprehensive versus selective primary health care: Lessons for global health policy. Health Affairs 2004, 23:167-176.

2. Gyawali B, Khanal P, Mishra SR, van Teijlingen E, Meyrowitsch DW: Building Strong Primary Health Care to Tackle the Growing Burden of Non-Communicable Diseases in Nepal. Global Health Action 2020, 13.

3. Gemelas JC: Post-ACA Trends in the US Primary Care Physician Shortage with Index of Relative Rurality. Journal of Rural Health 2020.

4. Yip W, Hsiao W: China's health care reform: A tentative assessment. China Economic Review 2009, 20:613-619.

5. Lu C, Zhang ZX, Lan XT: Impact of China's referral reform on the equity and spatial accessibility of healthcare resources: A case study of Beijing. Social Science \& Medicine 2019, 235.

6. Yang GH, Wang Y, Zeng YX, Gao GF, Liang XF, Zhou MG, Wan X, Yu SC, Jiang YH, Naghavi M, et al: Rapid health transition in China, 1990-2010: findings from the Global Burden of Disease Study 2010. Lancet 2013, 381:1987-2015.

7. Zheng A, Fang Q, Zhu Y, Jiang C, Jin F, Wang X: An application of ARIMA model for predicting total health expenditure in China from 1978-2022. Journal of Global Health 2020, 10.

8. Li JM, Chen XL, Han XL, Zhang GH: Spatiotemporal matching between medical resources and population ageing in China from 2008 to 2017. Bmc Public Health 2020, 20.

9. Xu X, Huang X, Zhang X, Chen L: Family Economic Burden of Elderly Chronic Diseases: Evidence from China. Healthcare (Basel) 2019, 7.

10. Yang GH, Kong LZ, Zhao WH, Wan X, Zhai Y, Chen LC, Koplan JP: Health System Reform in China 3 Emergence of chronic non-communicable diseases in China. Lancet 2008, 372:1697-1705.

11. Gong P, Liang S, Carlton EJ, Jiang QW, Wu JY, Wang L, Remais JV: Urbanisation and health in China. Lancet 2012, 379:843-852.

12. Opinions on Deepening the Reform of the Medical and Health Care System [http://www.gov.cn/test/2009-04/08/content_1280069.htm]

13. Shen X, Yang W, Sun S: Analysis of the Impact of China's Hierarchical Medical System and Online Appointment Diagnosis System on the Sustainable Development of Public Health: A Case Study of Shanghai. Sustainability 2019, 11.

14. Guidance on Promoting the Construction of Hierarchical Medical System [http://www.gov.cn/zhengce/content/2015-09/11/content_10158.htm]

15. Li MN, Zhang Y, Lu Y, Yu WY, Nong X, Zhang LL: Factors influencing two-way referral between hospitals and the community in China: A system dynamics simulation model. Simulation- 
Transactions of the Society for Modeling and Simulation International 2018, 94:765-782.

16. China NHCotPsRo: China Health Statistics Yearbook 2020. Peking Union Medical College Press; 2020.

17. Wang HHX, Wang JJ, Wong SYS, Wong MCS, Li FJ, Wang PX, Zhou ZH, Zhu CY, Griffiths SM, Mercer SW: Epidemiology of multimorbidity in China and implications for the healthcare system: crosssectional survey among 162,464 community household residents in southern China. Bmc Medicine 2014, 12.

18. Parry J: GP based primary care is only just starting to emerge in China. British Medical Journa/ 2010, 341.

19. Sun X, Sun T, Jin YS, Wang YP: Spatial Organization of Hierarchical Medical Services within the City Proper of Tianjin, China: Towards Efficient Medical Alliances. Sustainability 2019, 11.

20. Yip WC-M, Hsiao WC, Chen W, Hu S, Ma J, Maynard A: Early appraisal of China's huge and complex health-care reforms. Lancet 2012, 379:833-842.

21. Bhattacharyya O, Yin D, Wong ST, Chen B: Evolution of primary care in China 1997-2009. Health Policy 2011, 100:174-180.

22. Li J, Wang P, Kong X, Liang H, Zhang X, Shi L: Patient satisfaction between primary care providers and hospitals: a cross-sectional survey in Jilin province, China. International Journal for Quality in Health Care 2016, 28:346-354.

23. Xu XL, Zhou LL, Antwi HA, Chen X: Evaluation of health resource utilization efficiency in community health centers of Jiangsu Province, China. Human Resources for Health 2018, 16.

24. Huang MF, Wei DH, Rubino L, Wang LS, Li DZ, Ding BF, Li G: "Three essential elements" of the primary health care system: A comparison between California in the US and Guangdong in China. Family Medicine and Community Health 2015, 3:23-29.

25. Luo ZN, Bai X, Min R, Tang CM, Fang PQ: Factors influencing the work passion of Chinese community health service workers: an investigation in five provinces. Bmc Family Practice 2014, 15.

26. Ge CX, Fu JL, Chang Y, Wang L: Factors associated with job satisfaction among Chinese community health workers: a cross-sectional study. Bmc Public Health 2011, 11.

27. Zhang MJ, Yang RR, Wang W, Gillespie J, Clarke S, Yan F: Job satisfaction of urban community health workers after the 2009 healthcare reform in China: a systematic review. International Journal for Quality in Health Care 2016, 28:14-21.

28. Chin-Quee D, Mugeni C, Nkunda D, Uwizeye MR, Stockton LL, Wesson J: Balancing workload, motivation and job satisfaction in Rwanda: assessing the effect of adding family planning service provision to community health worker duties. Reproductive Health 2016, 13.

29. Liu GG, Vortherms SA, Hong X: China's Health Reform Update. In Annual Review of Public Health, Vol 38. Volume 38. Edited by Fielding JE; 2017: 431-448: Annual Review of Public Health].

30. Sternberg RJ: Implicit Theories of Intelligence, Creativity, and Wisdom. Journal of Personality and Social Psychology 1985, 49:607-627. 
31. Dweck CS, Chiu CY, Hong YY: Implicit Theories and Their Role in Judgments and Reactions - a World from 2 Perspectives. Psychological Inquiry 1995, 6:267-285.

32. Burnette JL, O'Boyle EH, VanEpps EM, Pollack JM, Finkel EJ: Mind-Sets Matter: A Meta-Analytic Review of Implicit Theories and Self-Regulation. Psychological Bulletin 2013, 139:655-701.

33. Schyns B, Kiefer T, Foti RJ: Does thinking of myself as leader make me want to lead? The role of congruence in self-theories and implicit leadership theories in motivation to lead. Journal of Vocational Behavior 2020, 122.

34. Lord RG, Epitropaki O, Foti RJ, Hansbrough TK: Implicit Leadership Theories, Implicit Followership Theories, and Dynamic Processing of Leadership Information. In Annual Review of Organizational Psychology and Organizational Behavior, Vol 7. Volume 7. Edited by Morgeson F; 2020: 49-74: Annual Review of Organizational Psychology and Organizational Behavior].

35. De France K, Hollenstein T: Implicit theories of emotion and mental health during adolescence: the mediating role of emotion regulation. Cognition \& Emotion.

36. Hu CS, Ferrari M, Liu RD, Gao Q, Weare E: Mainland Chinese Implicit Theory of Wisdom: Generational and Cultural Differences. Journals of Gerontology Series B-Psychological Sciences and Social Sciences 2018, 73:1416-1424.

37. Buckley J, O'Connor A, Seery N, Hyland T, Canty D: Implicit theories of intelligence in STEM education: perspectives through the lens of technology education students. International Journal of Technology and Design Education 2019, 29:75-106.

38. Gralewski J, Karwowski M: Are Teachers' Implicit Theories of Creativity Related to the Recognition of Their Students' Creativity? Journal of Creative Behavior 2018, 52:156-167.

39. Ashton MC, Lee $\mathrm{K}$ : A defence of the lexical approach to the study of personality structure. European Journal of Personality 2005, 19:5-24.

40. Saucier G, Goldberg LR: Lexical studies of indigenous personality factors: Premises, products, and prospects. Journal of Personality 2001, 69:847-879.

41. Gorbaniuk O, Budzinska A, Owczarek M, Bozek E, Juros K: The Factor Structure of Polish PersonalityDescriptive Adjectives: An Alternative Psycho-lexical Study. European Journal of Personality 2013, 27:304-318.

42. Thalmayer AG, Saucier G, Ole-Kotikash L, Payne D: Personality Structure in East and West Africa: Lexical Studies of Personality in Maa and Supyire-Senufo. Journal of Personality and Social Psychology 2020, 119:1132-1152.

43. De Vries RE: The Main Dimensions of Sport Personality Traits: A Lexical Approach. Frontiers in Psychology 2020, 11.

44. MoghaddamHosseini V, Makai A, Dweik D, Varnagy A: Factor analysis study of the Hungarian translation of Wijma Delivery Expectancy/Experience Questionnaire (version A). Current Psychology 2020, 39:1098-1105.

45. Zhang C, Zhang H, Zhao M, Liu D, Zhao Y, Yao Y: Assessment of Geriatric Depression Scale's Applicability in Longevous Persons based on Classical Test and Item Response Theory. Journal of 
Affective Disorders 2020, 274:610-616.

46. Anderson JC, Gerbing DW: STRUCTURAL EQUATION MODELING IN PRACTICE - A REVIEW AND RECOMMENDED 2-STEP APPROACH. Psychological Bulletin 1988, 103:411-423.

47. Golini N, Egidi V: The Latent Dimensions of Poor Self-Rated Health: How Chronic Diseases, Functional and Emotional Dimensions Interact Influencing Self-Rated Health in Italian Elderly. Social Indicators Research 2016, 128:321-339.

48. Fan N: Strategy Use in Second Language Vocabulary Learning and Its Relationships With the Breadth and Depth of Vocabulary Knowledge: A Structural Equation Modeling Study. Frontiers in Psychology 2020, 11.

49. Harerimana A, Mtshali NG: Using Exploratory and Confirmatory Factor Analysis to understand the role of technology in nursing education. Nurse Education Today 2020, 92.

50. Nikolaou P, Basbas S, Politis I, Borg G: Trip and Personal Characteristics towards the Intention to Cycle in Larnaca, Cyprus: An EFA-SEM Approach. Sustainability 2020, 12.

51. Joseph F, Hair J, William CB, Barry JB, Rolph EA: Multivariate Data Analysis. Edinburgh Gate: Pearson Education Limited; 2014.

52. Anand S, Barnighausen T: Health workers at the core of the health system: Framework and research issues. Health Policy 2012, 105:185-191.

53. Head B, Middleton A, Zeigler C: Work Satisfaction Among Hospice and Palliative Nurses. Journal of Hospice \& Palliative Nursing 2019, 21:E1-E11.

54. Vikstrom S, Johansson K: Professional pride: A qualitative descriptive study of nursing home staff's experiences of how a quality development project influenced their work. Journal of Clinical Nursing 2019, 28:2760-2768.

55. Valizadeh L, Zamanzadeh V, Habibzadeh H, Alilu L, Gillespie M, Shakibi A: Threats to nurses' dignity and intent to leave the profession. Nursing Ethics 2018, 25:520-531.

56. Yang J, Guo A, Wang Y, Zhao Y, Yang X, Li H, Duckitt R, Liang W: Human Resource Staffing and Service Functions of Community Health Services Organizations in China. Annals of Family Medicine 2008, 6:421-427.

57. Uncu Y, Bayram N, Bilgel N: Job related affective well-being among primary health care physicians. European Journal of Public Health 2007, 17:514-519.

58. Morrissy L, Boman P, Mergler A: Nursing a Case of the Blues: An Examination of the Role of Depression in Predicting Job-Related Affective Well-Being in Nurses. Issues in Mental Health Nursing 2013, 34:158-168.

59. Willemse BM, De Jonge J, Smit D, Visser Q, Depla MFIA, Pot AM: Staff's person-centredness in dementia care in relation to job characteristics and job-related well-being: a cross-sectional survey in nursing homes. Journal of Advanced Nursing 2015, 71:404-416.

60. Drebing C, McCarty EF, Lombardo NBE: Professional caregivers for patients with dementia: predictors of job and career commitment. American journal of Alzheimer's disease and other dementias 2002, 
17:357-366.

61. Vernooij-Dasssen MJ, Faber MJ, Rikkert MGO, Koopmans RT, van Achterberg T, Braat DD, Raas GP, Wollersheim H: Dementia care and labour market: The role of job satisfaction. Aging \& Mental Health 2009, 13:383-390.

62. Pizarro JP, Martin ME, Di Giusto C: Adolescents Work Values. Revista De Psicodidactica 2011, 16:381-399.

63. Luo Z, Bai X, Min R, Tang C, Fang P: Factors influencing the work passion of Chinese community health service workers: an investigation in five provinces. Bmc Family Practice 2014, 15.

64. Liu JA, Wang Q, Lu ZX: Job satisfaction and its modeling among township health center employees: a quantitative study in poor rural China. Bmc Health Services Research 2010, 10.

65. Wang $H$, Jin $Y$, Wang $D$, Zhao $S$, Sang $X$, Yuan B: Job satisfaction, burnout, and turnover intention among primary care providers in rural China: results from structural equation modeling. Bmc Family Practice 2020, 21.

66. Lu Y, Hu X-M, Huang X-L, Zhuang X-D, Guo P, Feng L-F, Hu W, Chen L, Zou H, Hao Y-T: The relationship between job satisfaction, work stress, work-family conflict, and turnover intention among physicians in Guangdong, China: a cross-sectional study. Bmj Open 2017, 7.

67. Willard-Grace R, Hessler D, Rogers E, Dube K, Bodenheimer T, Grumbach K: Team Structure and Culture Are Associated With Lower Burnout in Primary Care. Journal of the American Board of Family Medicine 2014, 27:229-238.

68. Espasandin-Bustelo F, Ganaza-Vargas J, Diaz-Carrion R: Employee happiness and corporate social responsibility: the role of organizational culture. Employee Relations.

69. Li W, Gan Y, Dong X, Zhou Y, Cao S, Kkandawire N, Cong Y, Sun H, Lu Z: Gatekeeping and the utilization of community health services in Shenzhen, China A cross-sectional study. Medicine 2017, 96.

70. Zhang WW, Ung COL, Lin GH, Liu J, Li WJ, Hu H, Xi XY: Factors Contributing to Patients' Preferences for Primary Health Care Institutions in China: A Qualitative Study. Frontiers in Public Health 2020, 8.

71. Van der Doef M, Maes S: The Job Demand-Control(-Support) model and psychological well-being: a review of 20 years of empirical research. Work and Stress 1999, 13:87-114.

72. Haeusser JA, Mojzisch A, Niesel M, Schulz-Hardt S: Ten years on: A review of recent research on the Job Demand-Control (-Support) model and psychological well-being. Work and Stress 2010, 24:1-35.

73. Kwok SYCL, Cheng L, Wong DFK: Family Emotional Support, Positive Psychological Capital and Job Satisfaction Among Chinese White-Collar Workers. Journal of Happiness Studies 2015, 16:561-582.

74. Chan XW, Kalliath P, Chan C, Kalliath T: How does family support facilitate job satisfaction? Investigating the chain mediating effects of work-family enrichment and job-related well-being. Stress and Health 2020, 36:97-104.

75. Nei D, Snyder LA, Litwiller BJ: Promoting retention of nurses A meta-analytic examination of causes of nurse turnover. Health Care Management Review 2015, 40:237-253. 
76. Yu J, Song H, Shi H, Wang K: Association between work-family conflict and overall well-being among Chinese nurse leaders. Journal of Nursing Management 2020, 28:1498-1503.

77. Hoffner CA, Levine KJ, Toohey RA: Socialization to work in late adolescence: The role of television and family. Journal of Broadcasting \& Electronic Media 2008, 52:282-302.

78. Sang TQ, Zhou HL, Li MH, Li WT, Shi HB, Chen HB, Zhou HG: Investigation of the differences between the medical personnel's and general population's view on the doctor-patient relationship in China by a cross-sectional survey. Globalization and Health 2020, 16.

79. Cao J, Wei J: Evolution of the perception of the doctor's role in China. Lancet 2014, 384:742-742.

80. Cai R, Tang J, Deng C, Lv G, Xu X, Sylvia S, Pan J: Violence against health care workers in China, 2013-2016: evidence from the national judgment documents. Human Resources for Health 2019, 17.

81. Zeng Y, Zhang L, Yao G, Fang Y: Analysis of current situation and influencing factor of medical disputes among different levels of medical institutions based on the game theory in Xiamen of China A cross-sectional survey. Medicine 2018, 97.

82. Zucker NA, Schmitt C, DeJonckheere MJ, Nichols LP, Plegue MA, Chang T: Confidentiality in the Doctor-Patient Relationship: Perspectives of Youth Ages 14-24 Years. Journal of Pediatrics 2019, 213:196-202.

83. Shi Y, Xue H, Ma Y, Wang L, Gao T, Shi L, Wang Y, Cui M, Wang C, Yang X, et al: Prevalence of occupational exposure and its influence on job satisfaction among Chinese healthcare workers: a large-sample, cross-sectional study. Bmj Open 2020, 10.

84. Du Y, Wang W, Washburn DJ, Lee S, Towne SD, Jr., Zhang H, Maddock JE: Violence against healthcare workers and other serious responses to medical disputes in China: surveys of patients at 12 public hospitals. Bmc Health Services Research 2020, 20.

85. Chou L-P, Li C-Y, Hu SC: Job stress and burnout in hospital employees: comparisons of different medical professions in a regional hospital in Taiwan. Bmj Open 2014, 4.

86. Moreno-Jimenez B, Galvez-Herrer M, Rodriguez-Carvajal R, Vergel AIS: A study of physicians' intention to quit: The role of burnout, commitment and difficult doctor-patient interactions. Psicothema 2012, 24:263-270.

87. Gan Y, Gong YH, Chen YW, Cao SY, Li LQ, Zhou YF, Herath C, Li WZ, Song XY, Li J, et al: Turnover intention and related factors among general practitioners in Hubei, China: a cross-sectional study. Bmc Family Practice 2018, 19.

88. Choi SL, Goh CF, Adam MBH, Tan OK: Transformational leadership, empowerment, and job satisfaction: the mediating role of employee empowerment. Human Resources for Health 2016, 14.

89. Chen Y, Zahedi FM: INDIVIDUALS' INTERNET SECURITY PERCEPTIONS AND BEHAVIORS: POLYCONTEXTUAL CONTRASTS BETWEEN THE UNITED STATES AND CHINA. Mis Quarterly 2016, 40:205-+.

90. Fornell C, Larcker DF: EVALUATING STRUCTURAL EQUATION MODELS WITH UNOBSERVABLE VARIABLES AND MEASUREMENT ERROR. Journal of Marketing Research 1981, 18:39-50. 
91. Podsakoff PM, Organ DW: SELF-REPORTS IN ORGANIZATIONAL RESEARCH - PROBLEMS AND PROSPECTS. Journal of Management 1986, 12:531-544.

92. Zhao X, Lynch JG, Jr., Chen Q: Reconsidering Baron and Kenny: Myths and Truths about Mediation Analysis. Journal of Consumer Research 2010, 37:197-206.

93. Preacher KJ, Hayes AF: Asymptotic and resampling strategies for assessing and comparing indirect effects in multiple mediator models. Behavior Research Methods 2008, 40:879-891.

94. Zhang M, Yan F, Wang W, Li G: Is the effect of person-organisation fit on turnover intention mediated by job satisfaction? A survey of community health workers in China. Bmj Open 2017, 7.

95. Jin YZ, Wang HP, Wang D, Yuan BB: Job satisfaction of the primary healthcare providers with expanded roles in the context of health service integration in rural China: a cross-sectional mixed methods study. Human Resources for Health 2019, 17.

96. Liu J, Zhu B, Wu J, Mao Y: Job satisfaction, work stress, and turnover intentions among rural health workers: a cross-sectional study in 11 western provinces of China. Bmc Family Practice 2019, 20.

\section{Tables}

Table 1. Reliability and validity test 


\begin{tabular}{|c|c|c|c|c|c|}
\hline Factors & Items & $\begin{array}{l}\text { Standardized } \\
\text { factor loading }\end{array}$ & $\mathrm{CR}$ & AVE & $\begin{array}{l}\text { cronbach } \\
\text { alpha }\end{array}$ \\
\hline \multirow{5}{*}{$\begin{array}{l}\text { Condition of the City Where } \\
\text { the PMHCl Is Located } \\
\text { CCPL }\end{array}$} & Development & 0.866 & 0.897 & 0.637 & 0.861 \\
\hline & Environment & 0.848 & & & \\
\hline & $\begin{array}{l}\text { Culture and } \\
\text { Customs }\end{array}$ & 0.762 & & & \\
\hline & Transportation & 0.758 & & & \\
\hline & Location & 0.748 & & & \\
\hline \multirow{11}{*}{$\begin{array}{l}\text { Remuneration and } \\
\text { Development } \\
\text { RD }\end{array}$} & Working Bonus & 0.867 & 0.951 & 0.638 & 0.951 \\
\hline & Medical Insurance & 0.853 & & & \\
\hline & Working Subsidy & 0.846 & & & \\
\hline & $\begin{array}{l}\text { Performance } \\
\text { Assessment }\end{array}$ & 0.807 & & & \\
\hline & $\begin{array}{l}\text { Professional Title } \\
\text { Promotion }\end{array}$ & 0.803 & & & \\
\hline & $\begin{array}{l}\text { Social Insurance } \\
\text { and Accumulation }\end{array}$ & 0.792 & & & \\
\hline & Wage & 0.787 & & & \\
\hline & $\begin{array}{l}\text { Holidays } \\
\text { Arrangements }\end{array}$ & 0.779 & & & \\
\hline & Authorized Strength & 0.754 & & & \\
\hline & Position Promotion & 0.749 & & & \\
\hline & $\begin{array}{l}\text { Individual } \\
\text { Development }\end{array}$ & 0.737 & & & \\
\hline \multirow{6}{*}{$\begin{array}{l}\text { Internal Organization } \\
\text { Development } \\
\text { IOD }\end{array}$} & $\begin{array}{l}\text { Software and } \\
\text { Hardware Facilities }\end{array}$ & 0.835 & 0.897 & 0.592 & 0.895 \\
\hline & $\begin{array}{l}\text { Specialist } \\
\text { Construction }\end{array}$ & 0.801 & & & \\
\hline & $\begin{array}{l}\text { Learning } \\
\text { Atmosphere }\end{array}$ & 0.788 & & & \\
\hline & $\begin{array}{l}\text { Human resource } \\
\text { allocation }\end{array}$ & 0.752 & & & \\
\hline & $\begin{array}{l}\text { Teaching and } \\
\text { scientific research }\end{array}$ & 0.727 & & & \\
\hline & Department Setting & 0.706 & & & \\
\hline
\end{tabular}




\begin{tabular}{|c|c|c|c|c|c|}
\hline \multirow{4}{*}{$\begin{array}{l}\text { Job Responsibilities } \\
\text { JR }\end{array}$} & Working Intensity & 0.921 & 0.909 & 0.715 & 0.907 \\
\hline & Working Stress & 0.889 & & & \\
\hline & Working Hours & 0.782 & & & \\
\hline & Workload & 0.780 & & & \\
\hline \multirow{4}{*}{$\begin{array}{l}\text { Family Support } \\
\text { FS }\end{array}$} & House & 0.858 & 0.883 & 0.654 & 0.882 \\
\hline & Parents & 0.814 & & & \\
\hline & Children & 0.784 & & & \\
\hline & Spouse & 0.775 & & & \\
\hline \multirow{4}{*}{$\begin{array}{l}\text { Patient Factor } \\
\text { PF }\end{array}$} & $\begin{array}{l}\text { Respect in } \\
\text { Physician }\end{array}$ & 0.832 & 0.866 & 0.617 & 0.862 \\
\hline & $\begin{array}{l}\text { Patient-Doctor } \\
\text { Relationship }\end{array}$ & 0.806 & & & \\
\hline & Trust in Physician & 0.760 & & & \\
\hline & $\begin{array}{l}\text { Moral Character of } \\
\text { Patients }\end{array}$ & 0.741 & & & \\
\hline \multirow{3}{*}{$\begin{array}{l}\text { Sense of Gain } \\
\text { SG }\end{array}$} & $\begin{array}{l}\text { Fulfilling Personal } \\
\text { Value }\end{array}$ & 0.849 & 0.859 & 0.670 & 0.858 \\
\hline & Professional Pride & 0.833 & & & \\
\hline & $\begin{array}{l}\text { Job-Related Well- } \\
\text { being }\end{array}$ & 0.772 & & & \\
\hline
\end{tabular}

Table 2. Discriminant validity of constructs

\begin{tabular}{|llllllll|}
\hline & F1 & F2 & F3 & F4 & F5 & F6 & F7 \\
\hline CCPL & $\mathbf{0 . 7 9 8}$ & & & & & & \\
\hline RD & 0.689 & $\mathbf{0 . 7 9 9}$ & & & & & \\
\hline IOD & 0.610 & 0.637 & $\mathbf{0 . 7 6 9}$ & & & & \\
\hline JR & 0.305 & 0.232 & 0.262 & $\mathbf{0 . 8 4 5}$ & & & \\
\hline FS & 0.498 & 0.459 & 0.329 & 0.275 & $\mathbf{0 . 8 0 8}$ & & \\
SG & 0.597 & 0.625 & 0.611 & 0.209 & 0.448 & $\mathbf{0 . 8 1 9}$ & \\
\hline PF & 0.669 & 0.694 & 0.645 & 0.319 & 0.512 & 0.770 & $\mathbf{0 . 7 8 6}$ \\
\hline
\end{tabular}


Table 3. Common method bias test.

\begin{tabular}{|llllllll|}
\hline & & $\mathrm{df}$ & $/ d f$ & RMSEA & CFI & TLI & IFI \\
\hline Without common method factor & 2535.443 & 608 & 4.170 & 0.060 & 0.921 & 0.913 & 0.921 \\
\hline With common method factor & 2507.799 & 661 & 4.100 & 0.059 & 0.922 & 0.915 & 0.922 \\
\hline
\end{tabular}

Table 4. The fit of the structural equation model

\begin{tabular}{|lllllll|}
\hline & $\mathrm{df}$ & /df & RMSEA & CFI & TLI & IFI \\
\hline 1988.127 & 611 & 3.254 & 0.050 & 0.943 & 0.938 & 0.943 \\
\hline
\end{tabular}

Table 5. Analysis of mediating effect

\begin{tabular}{|c|c|c|c|c|c|c|c|c|}
\hline \multirow[t]{2}{*}{ 吅 } & \multirow[t]{2}{*}{ प्रा } & \multirow[t]{2}{*}{$\begin{array}{l}\text { Boot } \\
\text { SE }\end{array}$} & \multirow[t]{2}{*}{ Z } & \multirow[t]{2}{*}{$P$} & \multicolumn{2}{|c|}{$\begin{array}{l}\text { Bias-Corrected } \\
95 \% \mathrm{Cl}\end{array}$} & \multicolumn{2}{|c|}{$\begin{array}{l}\text { Percentile } \\
95 \% \mathrm{Cl}\end{array}$} \\
\hline & & & & & Lower & Upper & Lower & Upper \\
\hline $\operatorname{lnt} 1^{a}$ & 0.252 & 0.046 & 5.478 & $<0.001$ & 0.169 & 0.351 & 0.167 & 0.347 \\
\hline $\operatorname{lnt} 2^{b}$ & 0.042 & 0.021 & 2.000 & 0.046 & 0.004 & 0.087 & 0.001 & 0.084 \\
\hline $\operatorname{lnt} 3^{C}$ & 0.064 & 0.028 & 2.286 & 0.011 & 0.011 & 0.123 & 0.009 & 0.120 \\
\hline $\operatorname{lnt} 4^{d}$ & 0.206 & 0.037 & 5.568 & $<0.001$ & 0.142 & 0.289 & 0.140 & 0.286 \\
\hline $\operatorname{lnt5} 5^{e}$ & -0.016 & 0.011 & -1.455 & 0.147 & -0.038 & 0.004 & -0.038 & 0.004 \\
\hline $\operatorname{lnt} 6^{f}$ & 0.044 & 0.020 & 2.200 & 0.028 & 0.008 & 0.089 & 0.006 & 0.086 \\
\hline $\begin{array}{l}\text { Total Indirect } \\
\text { Effect }\end{array}$ & 0.593 & 0.069 & 8.594 & $<0.001$ & 0.462 & 0.732 & 0.457 & 0.730 \\
\hline
\end{tabular}

a: Condition of the City where PMHC Located $\rightarrow$ Patient's attitude to PMHC $\rightarrow$ Sense of Gain

b: Condition of the City where PMHC Located $\rightarrow$ Family Support $\rightarrow$ Sense of Gain

c: Condition of the City where PMHC Located $\rightarrow$ Remuneration and Development $\rightarrow$ Sense of Gain

d: Condition of the City where PMHC Located $\rightarrow$ Patient's attitude to PMHC $\rightarrow$ Sense of Gain

e: Condition of the City where PMHC Located $\rightarrow$ Job Responsibilities $\rightarrow$ Sense of Gain 
Figures

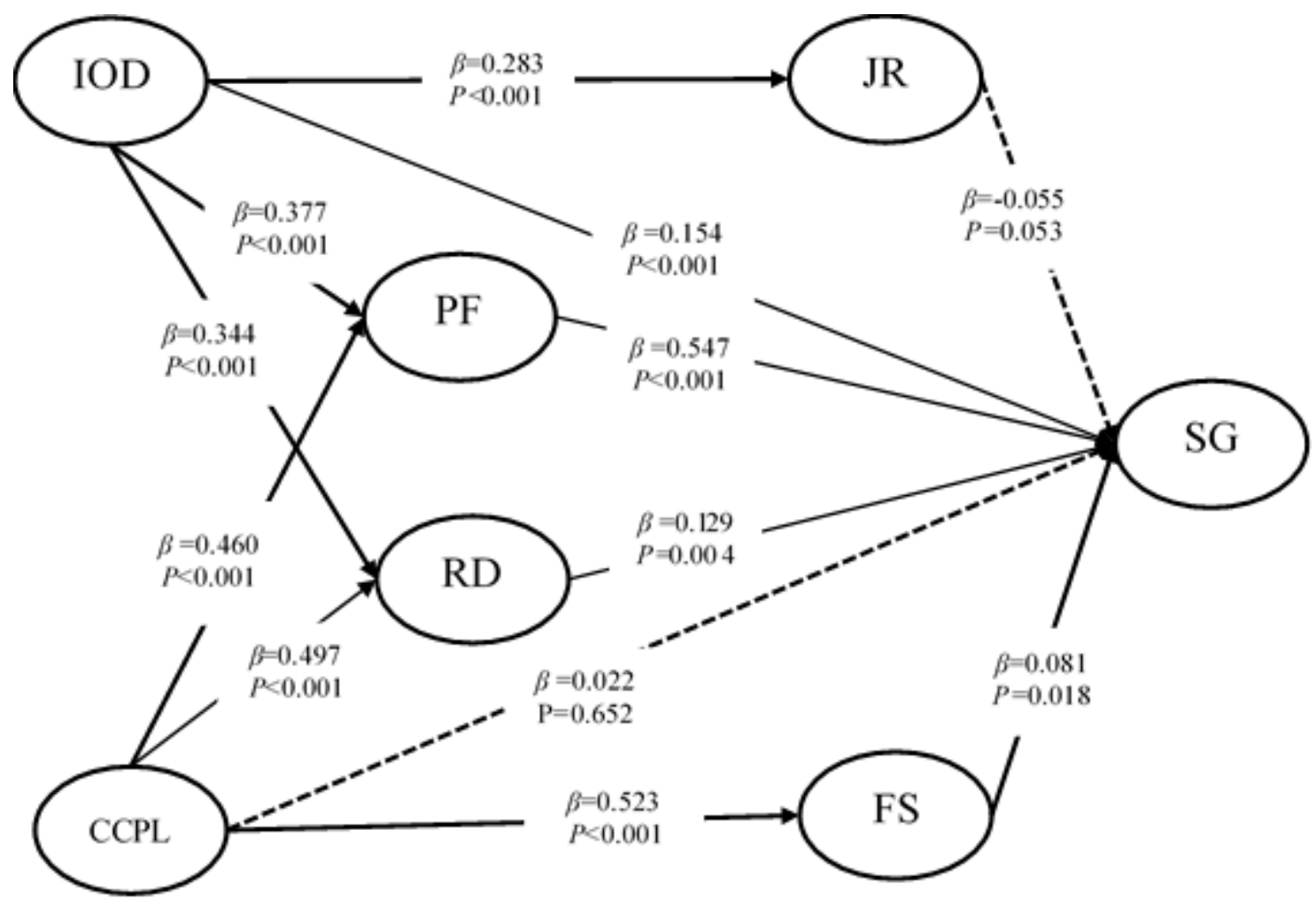

Figure 1

The structural model of the influencing factors.

\section{Supplementary Files}

This is a list of supplementary files associated with this preprint. Click to download.

- SupplementaryMaterial.xlsx 